\section{Vital corner of diagnostic challenge: eosinophilic granulomatosis with polyangiitis or COVID-19 pneumonia?}

The COVID-19 pandemic raises many alarms in the rheumatological era. Gianfrancesco et al reported the answer of an important question: the characteristics associated with hospitalization for COVID-19 in people with rheumatic disease. ${ }^{1}$ The data suggested that patients with rheumatic disease on prednisone dose of $\geq 10 \mathrm{mg} /$ day were associated with higher odds of hospitalization, and vasculitis was the fourth common rheumatic disease among all of these patients.

Another essential concept is to be careful in the differential diagnosis of the patients presenting with symptoms and signs of COVID-19. Physicians should keep in mind the other infectious and inflammatory diseases during diagnostic procedures of these critical patients. Inevitably, COVID-19 ranks first in differential diagnosis of all patients with respiratory symptoms and signs in current pandemic days. The standard of reference for confirming COVID-19 relies on microbiological tests, such as real-time reverse transcription polymerase chain reaction (RT-PCR). ${ }^{2}$ A systematic review of the accuracy of COVID-19 tests reported false-negative rates up to $29 \%$ (equating to a sensitivity of 71-98\%), based on negative RT-PCR tests which could turn out positive on repeated testing. ${ }^{3}$ Chest CT can be used as an auxiliary to RT-PCR for diagnosing COVID-19 pneumonia in the current pandemic context. ${ }^{4}$ The main CT feature of COVID-19 pneumonia is the bilateral patchy ground-glass opacities (GGOs) with peripheral predominance. ${ }^{5}$ On the other hand, GGO has many causes and one of these is eosinophilic granulomatosis with polyangiitis (EGPA). Herein, we presented two patients who have been hospitalized with preliminary diagnosis of COVID-19 but diagnosed as EGPA in hospitalisation period for COVID-19.

\section{CASE 1}

A male patient in his 20s was admitted to the emergency department with complaints of shortness of breath, cough and sputum. In the medical history of the patient, he had asthma for 3 years but he did not receive any asthma treatment. His shortness of breath deteriorated in the last month. He had no contact with any suspected or confirmed COVID-19 patient. Physical examination showed normal body temperature but diffuse bilateral rhonchi, and pulse oximetry revealed an oxygen saturation of $90 \%$ on ambient air. The results of his laboratory tests were as follows: white blood cell count $\left(14.1 \times 10^{9} / \mathrm{L}\right.$ and eosinophil count $\left(2.89 \times 10^{9} \mathrm{~L}\right)$; haemoglobin level was 17.4 $\mathrm{g} / \mathrm{L}$ and $\mathrm{C}$ reactive protein $(26 \mathrm{mg} / \mathrm{L}$,$) . D-dimer, ferritin, eryth-$ rocyte sedimentation rate (ESR) and procalcitonin levels were normal. Nasopharyngeal swab was obtained from the patient for CoVID-19 RT-PCR after the chest CT revealed bilateral groundglass opacifications (figure 1A). Due to the pandemic, spirometry (an aerosolising procedure) was deferred/skipped. He was hospitalized due to oxygen supplementation requirement and chest CT findings compatible with COVID-19. Hydroxychloroquine and azithromycin were commenced. However, RT-PCR tests, on two occasions (at least 24 hours apart) turned out negative, and these agents were stopped after 48 hours. The patient's history of asthma and eosinophilia were remarkable but he had no skin rash and neurological, renal and cardiac symptoms. We thought the patient might have had EGPA. The antineutrophil cytoplasmic antibody (ANCA) test revealed perinuclear
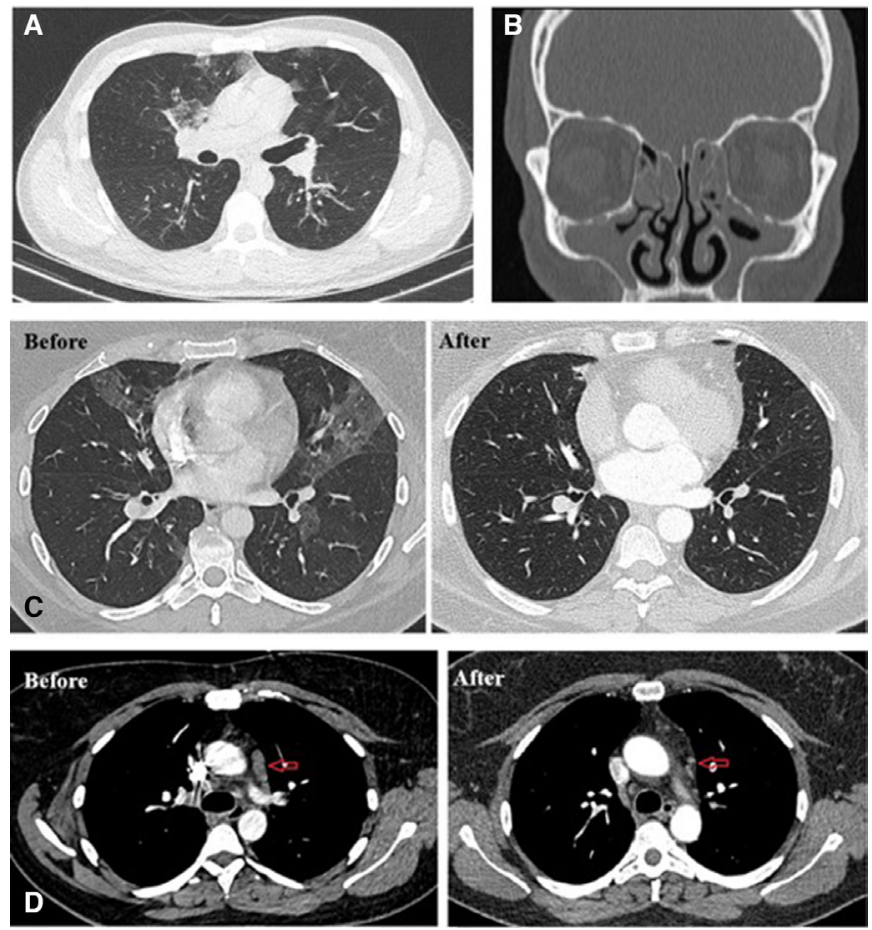

Figure 1 (A) Axial thorax CT image shows focal ground-glass opacities (B) Mucosal thickening and opacities are seen in ethmoid and maxillary sinuses. (C) Bilateral ground-glass opacifications that almost completely disappeared with corticosteroid on axial CT scans of the chest lung window (before and after treatment). (D) Lymph nodes that disappeared (red arrows) after treatment on axial CT scans of the chest mediastinal window (before and after treatment).

antineutrophil cytoplasmic antibody (p-ANCA)/myeloperoxidase (MPO) (1:100 titer) positive. Mucosal thickening and opacities were seen in ethmoid and maxillary sinuses on paranasal CT (figure 1B). EGPA was diagnosed depending on coexistence of asthma, eosinophilia in peripheral blood, MPO-ANCA positivity and paranasal CT abnormality (Table 1). We started treatment with $50 \mathrm{mg} /$ day prednisolone and inhaled corticosteroid and long-acting beta agonist (LABA) combination. His asthma was under control, and shortness of breath and eosinophilia regressed under this treatment. Prednisolone dose tapered to $20 \mathrm{mg} /$ day. No relapse has been observed yet at the first month control.

\section{CASE 2}

A female patient in her 40s with a history of untreated asthma for 20 years presented to the emergency department with shortness of breath, cough and wheezing. She was afebrile. Physical examination revealed diffuse rhonchi and pulse oximetry showed an oxygen saturation of $86 \%$ on ambient air. The results of her laboratory tests were as follows: white blood cell count $\left(13.2 \times 10^{9} / \mathrm{L}\right)$ and eosinophil count $\left(1.27 \times 10^{9} / \mathrm{L}\right.$, without any suspicion of parasitosis), C reactive protein $(17.4 \mathrm{~g} / \mathrm{L}), \mathrm{ESR}(55 \mathrm{~mm} / \mathrm{hour}$, and D-dimer $(0.78 \mathrm{mg} / \mathrm{L}$, normal range $0-0.55 \mathrm{mg} / \mathrm{L})$. Levels of haemoglobin, ferritin and procalcitonin were within normal range. Spirometry was not performed in the pandemic setting. Chest CT revealed bilateral focal GGOs and mediastinal lymph nodes (the largest one was $16 \times 7 \mathrm{~mm}$ ) (figure $1 \mathrm{C}, \mathrm{D}$ ). She was hospitalized with a preliminary diagnosis of COVID-19 and favipiravir was commenced. Other causes of GGO were investigated after the COVID-19 test results were negative twice and favipiravir was interrupted after 48 hours. Presence of both 


\begin{tabular}{|c|c|c|c|c|c|}
\hline $\begin{array}{l}1990 \text { ACR CCS classification criteria } \\
(4 / 6 \text { for classification })^{14}\end{array}$ & Case 1 & Case 2 & $\begin{array}{l}\text { Draft ACR/EULAR Criteria for EGPA } \\
(>5 \text { points for classification })^{15}\end{array}$ & $\begin{array}{l}\text { Case } 1 \text { (total } \\
\text { score: } 8 \text { ) }\end{array}$ & $\begin{array}{l}\text { Case } 2 \text { (total } \\
\text { score: } 11 \text { ) }\end{array}$ \\
\hline Asthma & Yes & Yes & Obstructive airways disease $(+3)$ & +3 & +3 \\
\hline Paranasal sinus abnormality & Yes & No & Nasal polyps (+3) & No & +3 \\
\hline $\begin{array}{l}\text { Mononeuropathy (including multiplex) or } \\
\text { polyneuropathy }\end{array}$ & No & No & Mononeuritis multiplex or motor neuropathy $(+1)$ & No & No \\
\hline $\begin{array}{l}\text { Eosinophilia }>10 \% \text { on differential white } \\
\text { blood cell count }\end{array}$ & Yes & Yes & Eosinophil count $>10^{9} / \mathrm{mL}(+5)$ & +5 & +5 \\
\hline $\begin{array}{l}\text { Biopsy containing a blood vessel with } \\
\text { extravascular eosinophils }\end{array}$ & Not done & Not done & $\begin{array}{l}\text { Extravascular eosinophil predominant inflammation/ } \\
\text { increased eosinophils in bone marrow (2) }\end{array}$ & Not done & Not done \\
\hline \multirow{3}{*}{$\begin{array}{l}\text { Non-fixed pulmonary infiltrates on } \\
\text { roentgenography }\end{array}$} & Yes & Yes & & & \\
\hline & & & Microscopic haematuria $(-1)$ & No & No \\
\hline & & & c-ANCA or PR3-antibody positivity $(-3)$ & Negative & Negative \\
\hline
\end{tabular}

ACR, American College of Rheumatology; c-ANCA, cytoplasmic antineutrophil cytoplasmic antibody; CSS, Churg-Strauss syndrome; EGPA, eosinophilic granulomatosis with polyangiitis; EULAR, European League Against Rheumatism.

asthma, recurrent episodes of sinusitis and nasal polyp surgery in the patient's medical history, and eosinophilia in peripheral blood raised the question of whether the patient had EGPA. ANCA tests results were negative. Paranasal CT showed a rightmaxillarysinus retention cyst. We diagnosed EGPA and put her on $50 \mathrm{mg} /$ day prednisolone and inhaled corticosteroid-LABA combination treatment. Asthma symptoms and eosinophilia resolved under treatment. Similarly, prednisolone dose tapered to $20 \mathrm{mg} /$ day. No relapse occurred (table 1).

In current pandemic days, COVID-19 positions the first in differential diagnosis of all patients with respiratory symptoms and signs. RT-PCR plays a vital role in the diagnosis of COVID19. However, its lower sensitivity, insufficient stability and relatively longer processing time can cause delay in disease control. Chest CT is another main diagnostic tool for COVID-19 with low turnaround time and high sensitivity. However, because of overlap of CT imaging findings between COVID-19 and other diseases, there may be false-positive cases of COVID-19 on chest CT. ${ }^{6}$

COVID-19 has different imaging manifestations on chest CT. Lesions at the early stage of COVID-19 are relatively localised and mainly manifest as inflammatory infiltration restricted to the peripheral regions of one or both lungs, exhibiting patchy or segmental pure GGOs with vascular dilation. ${ }^{7}$ Extension of GGOs, increased crazy paving pattern and consolidation may be seen in the progressive stage of the disease. Besides these findings, vascular dilatation, traction bronchiectasis, subpleural bands, air bronchogram, vacuolar sign and bronchus distortion are other common signs of COVID-19 pneumonia. On the other hand, pleural fluid, enlarged mediastinal lymph nodes, cavitation and tree in bud appearance are uncommon findings for COVID19. ${ }^{8}$ Although presence or absence of these findings can help in the diagnosis of COVID-19 pneumonia, different manifestations of COVID-19 can cause diagnostic challenge.

Presence of both central and peripheral focal GGOs and enlarged mediastinal lymph nodes on the CT images of our cases was atypical for COVID-19 pneumonia. Nevertheless, RT-PCR tests results were negative twice with 24-hour intervals. Furthermore, eosinophilia in peripheral blood in both cases is an unexpected feature of COVID-19. ${ }^{9}$ EGPA is a disease characterised by systemic necrotising vasculitis and eosinophilia that can occur in patients with asthma. Asthma is the major EGPA characteristic affecting $91 \%-100 \%$ of patients, most often before systemic vasculitis starts. ${ }^{10}$ While p-ANCA positivity is about $40 \%$ in patients with EGPA, c-ANCA positivity is less than $10 \% \cdot{ }^{11}$ EGPA was the more appropriate diagnosis since our cases had asthma history, eosinophilia and migratory infiltration in the lung.

To the best of our knowledge, there is only one case in the English medical literature who was hospitalised with suspicion of COVID-19 and was diagnosed with EGPA. In that case, the patient had eosinophilia, bilateral GGO in lung and skin lesion, but he had no asthma and ANCA tests results were negative. In addition, the skin biopsy specimen revealed perivascular infiltrates with eosinophils. ${ }^{12}$

In this pandemic situation, CT undoubtedly plays an important role in the early identification of COVID-19 pneumonia. Typical CT features include predominant peripheral GGOs with multifocal distribution. ${ }^{13}$ To investigate other causes of GGO in patients who have atypical CT findings for COVID-19 pneumonia with negative RT-PCR test result is important. In particular, asthma history and eosinophilia in peripheral blood prompt the need to be investigated for EGPA. Awareness of the similar clinical manifestations between EGPA and COVID-19 pneumonia is critical.

Emine Duran $\odot,{ }^{1}$ Levent Kilic, ${ }^{1}$ Gamze Durhan, ${ }^{2}$ Ahmet Çağkan Inkaya, ${ }^{3}$ Gulay Sain Guven, ${ }^{4}$ Gul Karakaya, ${ }^{5}$ Orhan Macit Ariyurek, ${ }^{2}$ Omer Karadag ${ }^{1,6}$

'Department of Internal Medicine, Division of Rheumatology, Hacettepe University Faculty of Medicine, Ankara, Turkey

${ }^{2}$ Department of Radiology, Hacettepe University Faculty of Medicine, Ankara, Turkey ${ }^{3}$ Department of Infectious Diseases, Hacettepe University Faculty of Medicine, Ankara, Turkey

${ }^{4}$ Department of Internal Medicine, Hacettepe University Faculty of Medicine, Ankara, Turkey

${ }^{5}$ Department of Chest Diseases, Division of Immunology and Allergy, Hacettepe University Faculty of Medicine, Ankara, Turkey

${ }^{6}$ Vasculitis Research Centre, Hacettepe University, Ankara, Turkey

Correspondence to Professor Omer Karadag, Department of Internal Medicine, Division of Rheumatology, Hacettepe University Faculty of Medicine, Ankara 06100, Turkey; omerkaradag@ymail.com

Contributors All authors contributed equally.

Funding The authors have not declared a specific grant for this research from any funding agency in the public, commercial or not-for-profit sectors.

Competing interests None declared.

Patient and public involvement Patients and/or the public were not involved in the design, conduct, reporting or dissemination plans of this research.

Patient consent for publication Obtained.

Provenance and peer review Not commissioned; internally peer reviewed. 
(2)

\section{OPEN ACCESS}

Open access This is an open access article distributed in accordance with the Creative Commons Attribution Non Commercial (CC BY-NC 4.0) license, which permits others to distribute, remix, adapt, build upon this work non-commercially, and license their derivative works on different terms, provided the original work is properly cited, appropriate credit is given, any changes made indicated, and the use is non-commercial. See: http://creativecommons.org/licenses/by-nc/4.0/.

(c) Author(s) (or their employer(s)) 2020. Re-use permitted under CC BY-NC. No commercial re-use. See rights and permissions. Published by BMJ.

\section{(D) Check for updates}

To cite Duran E, Kilic L, Durhan G, et al. Ann Rheum Dis Epub ahead of print: [please include Day Month Year]. doi:10.1136/annrheumdis-2020-218533

Received 9 July 2020

Accepted 10 July 2020

Ann Rheum Dis 2020;0:1-3. doi:10.1136/annrheumdis-2020-218533

ORCID iD

Emine Duran http://orcid.org/0000-0003-0257-1061

\section{REFERENCES}

1 Gianfrancesco M, Hyrich KL, Al-Adely S, et al. Characteristics associated with hospitalisation for COVID-19 in people with rheumatic disease: data from the COVID-19 global rheumatology alliance physician-reported registry. Ann Rheum Dis 2020;79:859-66.
2 Corman VM, Landt O, Kaiser M, et al. Detection of 2019 novel coronavirus (2019nCoV) by real-time RT-PCR. Euro Surveill 2020;25.

3 Arevalo-Rodriguez I, Buitrago-Garcia D, Simancas-Racines D, et al. False-negative results of initial RT-PCR assays for COVID-19: a systematic review. medrxiv 2020. $10.1101 / 2020.04 .16 .20066787$

4 Fang Y, Zhang H, Xie J, et al. Sensitivity of chest CT for COVID-19: comparison to RTPCR. Radiology 2020:200432.

5 Wang Y, Dong C, Hu Y, et al. Temporal changes of CT findings in 90 patients with COVID-19 pneumonia: a longitudinal study. Radiology 2020:200843.

6 Ai T, Yang Z, Hou H, et al. Correlation of chest CT and RT-PCR testing in coronavirus disease 2019 (COVID-19) in China: a report of 1014 cases. Radiology 2020:26:200642.

7 Shi H, Han X, Jiang N, et al. Radiological findings from 81 patients with COVID-19 pneumonia in Wuhan, China: a descriptive study. Lancet Infect Dis 2020;20:425-34.

8 Chung M, Bernheim A, Mei X, et al. CT imaging features of 2019 novel coronavirus (2019-nCoV). Radiology 2020;295:202-7.

9 Lindsley AW, Schwartz JT, Rothenberg ME. Eosinophil responses during COVID-19 infections and coronavirus vaccination. J Allergy Clin Immunol 2020;146:1-7.

10 Nguyen Y, Guillevin L. Eosinophilic granulomatosis with polyangiitis (Churg-Strauss). Semin Respir Crit Care Med 2018;39:471-81.

11 Radice A, Bianchi L, Sinico RA. Anti-neutrophil cytoplasmic autoantibodies: methodological aspects and clinical significance in systemic vasculitis. Autoimmun Rev 2013:12:487-95.

12 Hashizume H, Sano Y, Furukawa S, et al. Eosinophilic granulomatosis with polyangiitis mimicking coronavirus disease 2019: a case report. J Eur Acad Dermatol Venereol 2020. doi:10.1111/jdv.16705. [Epub ahead of print: 04 Jun 2020].

13 Hani C, Trieu NH, Saab I, et al. COVID-19 pneumonia: a review of typical CT findings and differential diagnosis. Diagn Interv Imaging 2020;101:263-8.

14 Masi AT, Hunder GG, Lie JT, et al. The American College of rheumatology 1990 criteria for the classification of Churg-Strauss syndrome (allergic granulomatosis and angiitis). Arthritis Rheum 1990;33:1094-100.

15 Robson J, Grayson P, Ponte C, et al. OP0021 draft classification criteria for the anca associated vasculitides. Annals of the Rheumatic Diseases 2018:77:60-1. 